\title{
A Landslide Displacement Prediction Method with Iteration-Based Combined Strategy
}

\author{
L. Li iD, S. X. Zhang, Y. Qiang, Z. Zheng, S. H. Li, and C. S. Xia \\ Civil Engineering College, Chongqing Three Gorges University, Chongqing 404100, China \\ Correspondence should be addressed to L. Li; lily6636694@163.com
}

Received 11 November 2020; Revised 22 December 2020; Accepted 26 December 2020; Published 15 January 2021

Academic Editor: Xinyu Xie

Copyright (c) $2021 \mathrm{~L}$. Li et al. This is an open access article distributed under the Creative Commons Attribution License, which permits unrestricted use, distribution, and reproduction in any medium, provided the original work is properly cited.

\begin{abstract}
Predicting landslide displacement is of great significance in geotechnical engineering. An iteration-based combined prediction method was proposed for predicting the landslide displacement in this paper. Firstly, the landslide displacement was predicted by 10 latest multivariable grey models, and then the final landslide displacement prediction value was obtained through an iterationbased combined strategy. Concurrently, the reliability of the quadratic programming-based combined prediction method (QPCPM) and the iteration-based combined prediction method (ICPM) was rigorously proved in this paper. In addition, the inapplicability conditions of the optimal weight-based combined prediction method (OWCPM) were pointed out. ICPM could be regarded as a simplified version of QPCPM. The Bazimen and Baishuihe landslides in the Three Gorges Reservoir area of China were used as numerical examples to elaborate the performance of ICPM. This paper also demonstrated the reliability of ICPM by considering the effects of rainfall and reservoir water level on landslide displacement. Overall, ICPM features in simple and easy calculation and has rosy engineering application prospects.
\end{abstract}

\section{Introduction}

The landslide time prediction is a common concern of geological engineers [1]. However, it is beset with difficulties to solve this problem at present. Although the inverse velocity method [2] has achieved some success in the landslide time prediction, its application effect is affected by the operator's operant level, and the theory also has some implausible aspects [3]. Given this, people turn to predict the landslide displacement to realize the warming of landslides indirectly. Prediction of landslide displacement plays a critical role in reducing the damage of landslide disaster. In recent years, prediction methods based on mathematical models have been popular topics in studying landslide displacement prediction $[4,5]$.

Many observations indicate that the landslide displacement is nonlinear and nonstationary and is related to groundwater and rainfall [6]. A support vector machinebased prediction method considering nonlinear characteristics of landslide displacement was developed by Feng et al. [7], and the method has been used to analyze the high rock slope of the permanent ship-lock of the Three Gorges project and the area deformation at depth in the Bachimen landslide in Fujian Province, China. In order to consider the instability of landslide displacement, a prediction method based on modified ensemble empirical mode decomposition and extreme learning machine was proposed [8]. The method showed promising results in predicting the landslide displacement of the Baishuihe landslide in the Three Gorges Reservoir area of China. A landslide displacement prediction method based on a multivariate chaotic extreme learning machine was developed for the sake of considering the impact of rainfall and groundwater on the displacement of the landslide [9]. These methods have successfully predicted the displacement of the Bazimen and Baishuihe landslides in the Three Gorges Reservoir area of China. Besides, a variety of landslide displacement prediction methods based on mathematical models have been proposed. As a case in point, a landslide displacement prediction method based on the neural network was proposed by Du and Yin [10] and obtained good prediction accuracy. Simultaneously, the prediction model based on the extreme learning adaptive 
neuro-fuzzy inference system [11] and the novel kernel extreme learning machine [12] can also be applied to landslide displacement. Undoubtedly, these prediction methods could achieve great results on specific issues. The essence of these methods is to extrapolate the mathematical model obtained by approximating the simulated value of the landslide displacement and the measured value to realize the prediction [13, 14]. Provided that people use different methods to predict landslide displacements simultaneously, they tend to trust the predicted values with the smallest simulated error. However, this approach also faces a dilemma that the better the simulated effect does not necessarily mean the better the predicted effect. It is incredibly challenging to select the best landslide displacement prediction model based on simulated results.

Undoubtedly, an accurate prediction method should have smaller simulated errors. The prediction methods with similar simulated errors have different performance on different samples, and there is no perfect prediction method that applies to all samples. In order to ensure the reliability of the landslide displacement prediction method, it may be a feasible way to predict the landslide displacement from the perspective of combined prediction [15, 16]. Unfortunately, there are relatively few studies on landslide displacement prediction based on the combined prediction strategy. A landslide displacement prediction method based on the combined method was developed by Li et al. [17]. The method was used to predict the landslide displacement of the Huanglongxicun landslide and the Saleshan landslide. However, due to the defects of the prediction method itself, the weights will appear negative, so this is one of the issues that this paper needs to solve.

This paper developed an iteration-based combined prediction method (ICPM) for landslide displacement prediction based on the above discussions. The feasibility and advantages of this approach have been demonstrated with rigorous mathematical formulas. The structure of this paper is as follows: in Section 2, ICPM developed in this paper was introduced; in Section 3, the Bazimen landslide and the Baishuihe landslide in the Three Gorges Reservoir area of China were used as numerical examples to present the effectiveness of the proposed method in this paper; finally, the conclusions were drawn.

\section{Methods}

In this section, ICPM for landslide displacement prediction was proposed. Firstly, two conditions for constructing a combined prediction method were given. Condition 1: the performance of the mathematical models used to establish the combined prediction method should not be too far apart because it is of little significance to establish a combined method by using models with significant performance differences. Condition 2: due to the fact that complex combined strategies tend to lose practicality, combined strategies should be as simple as possible. Then, according to condition 1 , this paper selected 10 different multivariable grey models to predict landslide displacement. The multivariate grey model is an essential type of the prediction method compared with neural networks and other prediction methods. The multivariate grey model has low complexity in the calculation and stable predicted results; thus, it can be applied to engineering practice. According to condition 2, a new combined method with relative low complexity in the calculation is put forward in this paper.

2.1. 10 Multivariable Grey Models. The grey prediction model is fundamental initially put forward by Deng and evolved from the original unvaried prediction model to the multivariate prediction model. Here, we introduced the original multivariate grey model GM $(1, \mathrm{~N})$.

Consider the observed data, $X=\left\{x_{1}^{(0)}, x_{2}^{(0)}, \ldots, x_{N}^{(0)}\right\}$, where $X_{1}^{(0)}$ is the dependent variable, $X_{2}^{(0)}, \ldots, X_{N}^{(0)}$ are the independent variables, and

$$
\begin{aligned}
& X_{1}^{(0)}=\left(x_{1}^{(0)}(1), x_{1}^{(0)}(2), \ldots, x_{1}^{(0)}(n)\right) \\
& X_{2}^{(0)}=\left(x_{2}^{(0)}(1), x_{2}^{(0)}(2), \ldots, x_{2}^{(0)}(n)\right) \\
& \vdots \\
& X_{N}^{(0)}=\left(x_{N}^{(0)}(1), x_{N}^{(0)}(2), \ldots, x_{N}^{(0)}(n)\right) .
\end{aligned}
$$

For the first-order accumulation of the observation set, equation (2) is obtained:

$$
X^{1}=\left\{X_{1}^{(1)}, X_{2}^{(1)}, \ldots, X_{N}^{(1)}\right\}
$$

where

$$
\begin{aligned}
X_{1}^{(1)} & =\left(x_{1}^{(1)}(1), x_{1}^{(1)}(2), \ldots, x_{1}^{(1)}(n)\right) \\
X_{2}^{(1)} & =\left(x_{2}^{(1)}(1), x_{2}^{(1)}(2), \ldots, x_{2}^{(1)}(n)\right) \\
\vdots & \\
X_{N}^{(1)} & =\left(x_{N}^{(1)}(1), x_{N}^{(1)}(2), \ldots, x_{N}^{(1)}(n)\right) \\
x_{i}^{(1)}(k) & =\sum_{j=1}^{k} x_{i}^{(1)}(j), \quad i=1,2, \ldots, N ; k=1,2, \ldots, n .
\end{aligned}
$$

$X^{1}$ can be described by the following differential equation [18]:

$$
\frac{\mathrm{d} X_{1}^{(1)}(t)}{\mathrm{d} t}+b_{1} X_{1}^{(1)}(t)=\sum_{i=2}^{N} b_{i} X_{i}^{(1)}(t),
$$

where $b_{i}(i=1,2, \ldots, N)$ is the coefficient, which can be estimated by least squares, i.e.,

$$
\left[b_{i}\right]=\left(B^{T} B\right)^{-1} B^{T} Y,
$$


where

$$
\begin{aligned}
& B=\left[\begin{array}{cccc}
-\frac{\left(X_{1}^{(1)}(1)+X_{1}^{(1)}(2)\right)}{2} & X_{2}^{(1)}(2) & \cdots & X_{N}^{(1)}(2) \\
-\frac{\left(X_{1}^{(1)}(2)+X_{1}^{(1)}(3)\right)}{2} & X_{2}^{(1)}(3) & \cdots & X_{N}^{(1)}(3) \\
\vdots & \vdots & \ddots & \vdots \\
-\frac{\left(X_{1}^{(1)}(n-1)+X_{1}^{(1)}(n)\right)}{2} & X_{2}^{(1)}(n) & \cdots & X_{N}^{(1)}(n)
\end{array}\right], \\
& Y=\left[\begin{array}{lllll}
X_{1}^{(0)}(2) & X_{1}^{(0)}(3) & \cdots & X_{1}^{(0)}(n)
\end{array}\right]^{T} \text {. }
\end{aligned}
$$

The initial value conditions are considered:

$$
\widehat{X}_{1}^{(1)}(1)=\widehat{X}_{1}^{(0)}(1)=X_{1}^{(0)}(1) \text {. }
$$

The solution of equation (4) can be obtained, and the fitted value $X^{1}$ can be obtained by substituting the parameters $b_{i}(i=1,2, \ldots, N)$, and the fitted value of the original sequence can be obtained by subtractive damage reduction:

$$
\widehat{X}_{1}^{(0)}(k)=\widehat{X}_{1}^{(1)}(k)-\widehat{X}_{1}^{(1)}(k-1), \quad k=2,3, \ldots, n .
$$

The GM $(1, N)$ has a clear principle and simple calculation, but it has limited accuracy in predicting complex time series in reality [19]. For this reason, some improved multivariate grey models have been proposed. The 10 latest multivariate grey prediction models were used in this paper to predict landslide displacement. Detailed information can be found in Table 1 . The 10 multivariate grey models in Table 1 were improvements to GM $(1, N)$.

To ensure that these 10 multivariate grey models (DGM, FDGM, GMCG, GMCN, GMCPQ, GMCT, NGBMC, NGM, OBGM, and RDGM) meet condition 1, the performance of these 10 prediction models is firstly compared through published data in literature references. The source of the reference data is given in Table 2. The data for all examples are divided into two parts: the simulated samples and the predicted samples. Model performance is measured by mean absolute percent error (MAPE), i.e.,

$$
\text { MAPE }=\frac{1}{n-1} \sum_{k=2}^{n} \frac{\left|\widehat{X}_{1}^{(0)}(k)-X_{1}^{(0)}(k)\right|}{X_{1}^{(0)}(k)} \times 100 \% .
$$

The smaller the MAPE is, the better the performance of the model will be.

The programs of the 10 multivariate grey models have been compiled on MATLAB and applied to the 9 cases in Table 2 and then combined equation (9) to measure the performance of each model. Figure 1 shows MAPE of the simulated samples and the predicted samples of the 10 models in 9 cases. As can be seen from Figure 1(a), the MAPE of the simulated samples of the 10 models is all within $6 \%$. The difference is not large. As can be seen from Figure 1(b), the MAPE of the predicted samples is significantly larger than that of the simulated samples, but the differences between the models are still small. Figure 2 shows a box plot of the 10 models. It can be seen from Figures 1 and 2 that although the performance of these 10 models has a certain gap, the differences are generally small.

2.2. The Combined Strategy. A combined strategy for predicting landslide displacement was proposed [17], which is called the optimal weight strategy. The strategy is derived as follows:

Using $m$ different models to predict landslide displacement and weighting with $\mathbf{w}$, the residual of the combined method can be written as follows:

$$
e(k)=\sum_{i=1}^{m} w_{i} \varepsilon_{i}(k)=\left[w_{1} w_{2} \cdots w_{m}\right]\left[\varepsilon_{1}(k) \varepsilon_{2}(k) \cdots \varepsilon_{m}(k)\right]^{T} .
$$

From equation (10), equation (11) can be obtained:

$$
\left.\begin{array}{rl}
e(k)^{2} & =e(k) e(k) \\
& {\left[w_{1} w_{2} \cdots w_{m}\right.}
\end{array}\right]\left[\begin{array}{cccc}
\varepsilon_{1}(k)^{2} & \varepsilon_{1}(k) \varepsilon_{2}(k) & \cdots & \varepsilon_{1}(k) \varepsilon_{m}(k) \\
\varepsilon_{2}(k) \varepsilon_{1}(k) & \varepsilon_{2}(k)^{2} & \cdots & \varepsilon_{2}(k) \varepsilon_{m}(k) \\
\vdots & \vdots & \ddots & \vdots \\
\varepsilon_{m}(k) \varepsilon_{1}(k) & \varepsilon_{m}(k) \varepsilon_{2}(k) & \cdots & \varepsilon_{m}(k)^{2}
\end{array}\right]\left[\begin{array}{c}
w_{1} \\
w_{2} \\
\vdots \\
w_{m}
\end{array}\right] .
$$

Further, the residual sum of squares is as follows:

$$
\begin{aligned}
& J=\sum_{k=1}^{n} e(k)^{2}=e(k) e(k) \\
& =\left[\begin{array}{ll}
w_{1} w_{2} & \cdots
\end{array} w_{m}\right]\left[\begin{array}{ccccc}
\sum_{k=1}^{n} \varepsilon_{1}(k)^{2} & \sum_{k=1}^{n} \varepsilon_{1}(k) \varepsilon_{2}(k) & \cdots & \sum_{k=1}^{n} \varepsilon_{1}(k) \varepsilon_{m}(k) \\
\sum_{k=1}^{n} \varepsilon_{2}(k) \varepsilon_{1}(k) & \sum_{k=1}^{n} \varepsilon_{2}(k)^{2} & \cdots & \sum_{k=1}^{n} \varepsilon_{2}(k) \varepsilon_{m}(k) \\
\vdots & \vdots & \ddots & \vdots \\
\sum_{k=1}^{n} \varepsilon_{m}(k) \varepsilon_{1}(k) & \sum_{k=1}^{n} \varepsilon_{m}(k) \varepsilon_{2}(k) & \cdots & \sum_{k=1}^{n} \varepsilon_{m}(k)^{2}
\end{array}\right]\left[\begin{array}{c}
w_{1} \\
w_{2} \\
\vdots \\
w_{m}
\end{array}\right] \\
& =\mathbf{w}^{T} \boldsymbol{\varepsilon} \mathbf{w} .
\end{aligned}
$$


TABLE 1: 10 latest multivariate grey prediction models.

\begin{tabular}{lcc}
\hline Full name & Abbreviation & Literature reference \\
\hline A discrete grey model having one order and $N$ variables & DGM & Ding [20] \\
Fractional discrete multivariate grey model & FDGM & Ma et al. [21] \\
The grey model with convolution integral & GMCG & Tien [18]; Ma and Liu [19] \\
Grey multivariable convolution model with new information priority accumulation & GMCN & Wu and Zhang [22] \\
The GMC (1,N) model with fractional order accumulation & GMCPQ & Wu et al. [23] \\
The grey model with convolution integral & GMCT & Tien [18]; Ma and Liu [19] \\
The nonlinear grey Bernoulli multivariate model with convolution integral & NGBMC & NGM et al. [24] \\
A novel multivariable grey prediction model & OBGM & Zeng et al. [25] \\
The OGM (1, N) model with a dynamic background-value coefficient & RDGM & Zheng and Li [26] \\
A novel recursive discrete multivariate grey prediction model & Ma and Liu [19] \\
\hline
\end{tabular}

Table 2: Source of the cases.

\begin{tabular}{lcc}
\hline Case & Source & Number of simulated sample data \\
\hline Case 1 & Ma and Liu [19] & 10 \\
Case 2 & Ma and Liu [19] & 9 \\
Case 3 & Ma et al. [24] & 10 \\
Case 5 & Ma et al. [24] & 19 \\
Case 6 & Ma et al. [24] & 14 \\
Case 7 & Wu and Zhang [22] & 8 \\
Case 8 & Zeng et al. [25] & 8 \\
Case 10 & Ma et al. [21] & 8 \\
Case 12 & Ma and Liu [27] & 12 \\
\hline
\end{tabular}

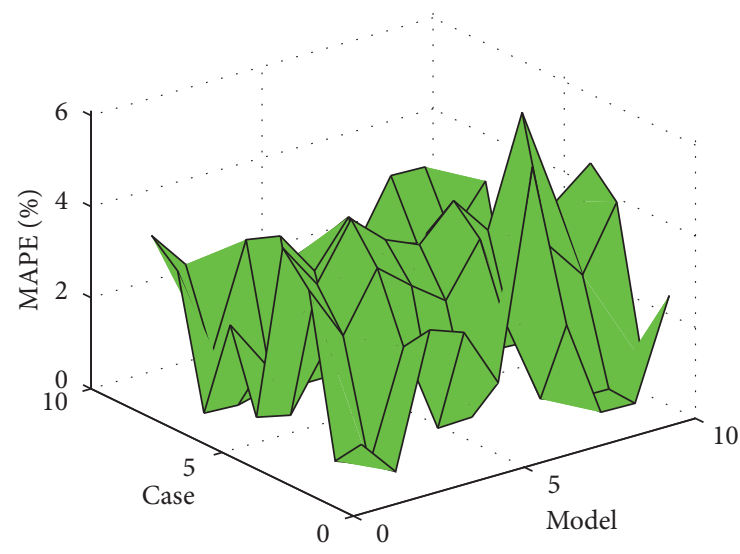

(a)

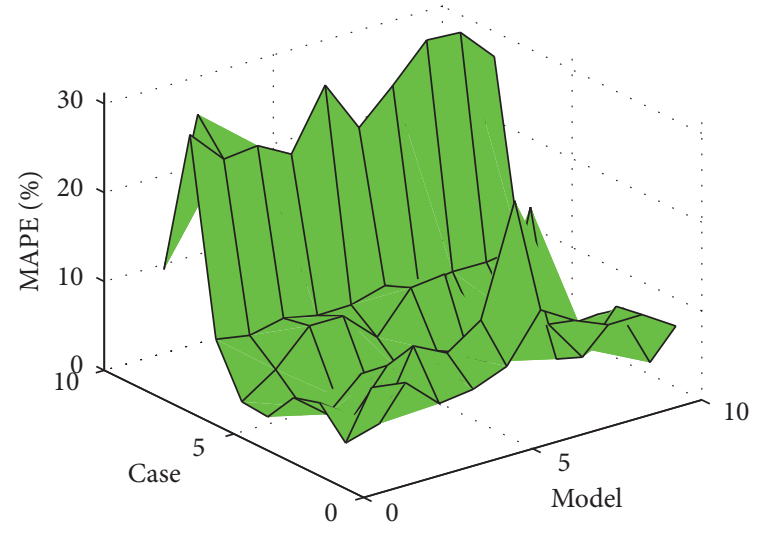

(b)

FIGURE 1: MAPE values for 10 models: (a) simulated samples; (b) predicted samples.

According to the Lagrange multiplier method, $\mathbf{w}$ can be solved by equation (12), i.e.,

$$
\mathbf{w}=\frac{\boldsymbol{\varepsilon}^{-1} \mathbf{R}}{\mathbf{R}^{T} \boldsymbol{\varepsilon}^{-1} \mathbf{R}} .
$$

Equation (13) is the combined strategy of Li et al. [17]. However, the equation does not restrict weight's positive and negative properties. The calculated value of equation (13) will appear negative, which does not meet the definition of the weight. A negative weight will also result in a large predicted error (refer to Section 2.3 or Section 3).
If the condition that "weight" cannot be negative is set in equation (12), the following mathematical problem can be obtained:

$$
\begin{array}{ll}
\min & \mathbf{w}^{T} \boldsymbol{\varepsilon} \mathbf{w}, \\
\text { s.t. } & \mathbf{w}^{T}=1, \\
& w_{i} \geq 0 .
\end{array}
$$

Equation (14) is a quadratic programming problem that often needs to be solved by numerical methods. This paper will give a simple combined strategy to avoid the 


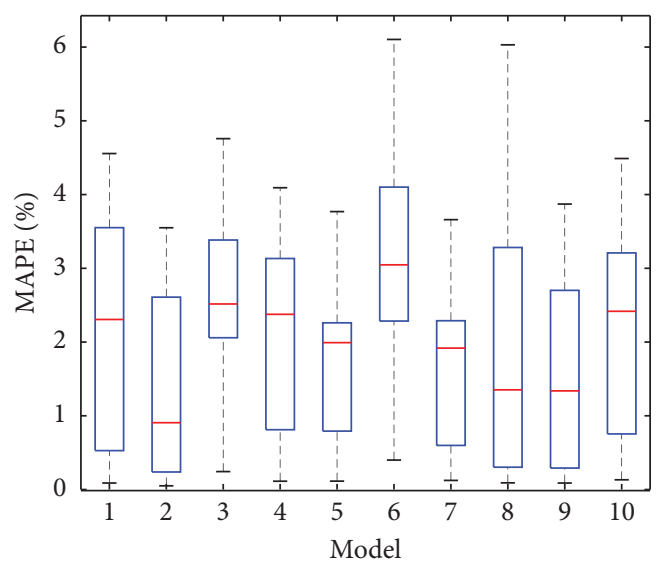

(a)

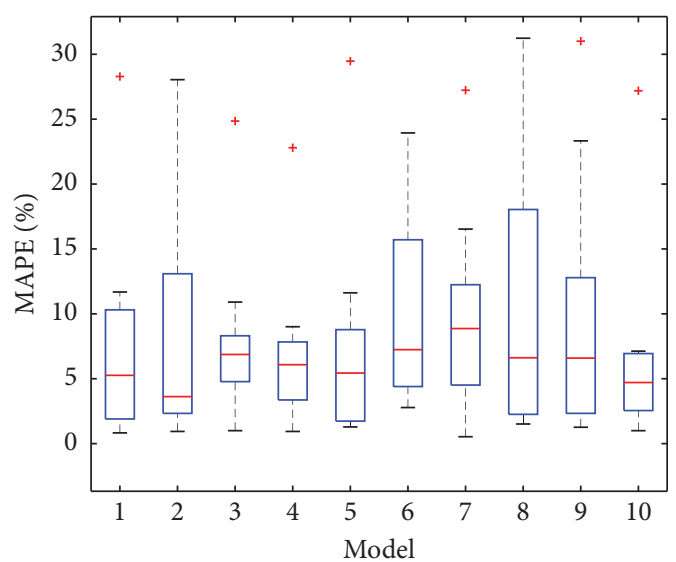

(b)

FIgURe 2: Performance comparison of 10 multivariate grey models: (a) simulated samples; (b) predicted samples.

complicated quadratic programming process. Firstly, a definition and a theorem were given.

Definition 1. When $w_{i}=1 / m$, the method is called the equal weight-based combined prediction method.

Theorem 1. $J_{a}$ is set to the sum of squares due to error (SSE) of the equal weight combined prediction method, and then $J_{a}<J_{\max }$ must be true, where $J_{\max }$ is the maximum SSE in all single prediction models.

Proof. According to the definition of the equal weight-based combined prediction method, equation (15) can be obtained:

$$
J_{a}=\mathbf{w}^{T} \boldsymbol{\varepsilon} \mathbf{w}=\frac{1}{m^{2}} \sum_{i=1}^{m} \sum_{j=1}^{m} \sum_{k=1}^{n} \varepsilon_{i}(k) \varepsilon_{j}(k) .
$$

From the Cauchy formula [28],

$$
\sum_{k=1}^{n} \varepsilon_{i}(k) \varepsilon_{j}(k)<\sqrt{\sum_{k=1}^{n} \varepsilon_{i}(k)^{2}} \sqrt{\sum_{k=1}^{n} \varepsilon_{j}(k)^{2}} \leq \sqrt{J_{\max }} \sqrt{J_{\max }} .
$$

That is,

$$
J_{a}<J_{\max }
$$

According to Theorem 1, we can design an iterationbased combined prediction strategy. The basic idea is to replace the value of the prediction model corresponding to $J_{\max }$ with the predicted value corresponding to $J_{a}$ until the algorithm converges (SSE is less than 0.001), i.e.,

$$
J_{a} \longrightarrow J_{\max }
$$

In this paper, the combined prediction methods established by equations (13)-(15) are, respectively, called the optimal weight-based combined prediction method (OWCPM), quadratic programming-based combined prediction method (QPCPM), and iteration-based combined prediction method (ICPM).

\subsection{Mathematical Properties of the Method}

Property 1. The simulated samples' SSE is least better than the worst single model.

Proof. Property 1 is obvious, so it will no longer be proved.

Property 2. It is impossible to estimate the upper bound of SSE in OWCPM's predicted samples. However, QPCPM and ICPM are at least better than the worst single model.

Proof. Set the weights of $m$ models to be $\left[w_{1}, w_{2}, \ldots, w_{m}\right]$. 


$$
\begin{aligned}
& J=\left[w_{1} w_{2} \cdots w_{m}\right]\left[\begin{array}{ccccc}
\sum_{k=1}^{n} \varepsilon_{1}(k)^{2} & \sum_{k=1}^{n} \varepsilon_{1}(k) \varepsilon_{2}(k) & \cdots & \sum_{k=1}^{n} \varepsilon_{1}(k) \varepsilon_{m}(k) \\
\sum_{k=1}^{n} \varepsilon_{2}(k) \varepsilon_{1}(k) & \sum_{k=1}^{n} \varepsilon_{2}(k)^{2} & \cdots & \sum_{k=1}^{n} \varepsilon_{2}(k) \varepsilon_{m}(k) \\
\vdots & \vdots & \ddots & \vdots \\
\sum_{k=1}^{n} \varepsilon_{m}(k) \varepsilon_{1}(k) & \sum_{k=1}^{n} \varepsilon_{m}(k) \varepsilon_{2}(k) & \cdots & \sum_{k=1}^{n} \varepsilon_{m}(k)^{2}
\end{array}\right]\left[\begin{array}{c}
w_{1} \\
w_{2} \\
\vdots \\
w_{m}
\end{array}\right] \\
& =\left[\begin{array}{cccc}
w_{1} \sum_{k=1}^{n} \varepsilon_{1}(k)^{2} & w_{1} \sum_{k=1}^{n} \varepsilon_{1}(k) \varepsilon_{2}(k) & \cdots & w_{1} \sum_{k=1}^{n} \varepsilon_{1}(k) \varepsilon_{m}(k) \\
w_{2} \sum_{k=1}^{n} \varepsilon_{2}(k) \varepsilon_{m}(k) & w_{2} \sum_{k=1}^{n} \varepsilon_{2}(k)^{2} & \cdots & w_{2} \sum_{k=1}^{n} \varepsilon_{2}(k) \varepsilon_{m}(k) \\
\vdots & \vdots & \ddots & \vdots \\
w_{m} \sum_{k=1}^{n} \varepsilon_{m}(k) \varepsilon_{1}(k) & w_{m} \sum_{k=1}^{n} \varepsilon_{m}(k) \varepsilon_{2}(k) & \cdots & w_{m} \sum_{k=1}^{n} \varepsilon_{m}(k)^{2}
\end{array}\right]\left[\begin{array}{c}
w_{1} \\
w_{2} \\
\vdots \\
w_{m}
\end{array}\right] \\
& \leq\left[\begin{array}{llll}
w_{1} & w_{2} & \cdots & w_{m}
\end{array}\right]\left[\begin{array}{cccc}
J_{\max } & J_{\max } & \cdots & J_{\max } \\
J_{\max } & J_{\max } & \cdots & J_{\max } \\
\vdots & \vdots & \ddots & \vdots \\
J_{\max } & J_{\max } & \cdots & J_{\max }
\end{array}\right]\left[\begin{array}{c}
w_{1} \\
w_{2} \\
\vdots \\
w_{m}
\end{array}\right]=J_{\max } .
\end{aligned}
$$

OWCPM could not guarantee that the inequality sign is established. However, QPCPM and ICPM could ensure that the inequality sign is established.

Property 1 and Property 2, respectively, answer the two questions of "why the combined prediction method is used" and "what advantage using combined prediction method has." From Property 1, it can be further obtained that SSE of OWCPM for simulated samples is the smallest. Unfortunately, Property 2 directly indicates that OWCPM is unreliable. Although QPCPM and ICPM are reliable, the latter is much simpler. ICPM could be regarded as a simplified version of QPCPM. In summary, engineers have the confidence to use ICPM in actual engineering.

2.4. Calculation Flow Chart. The calculation flow chart of ICPM is shown in Figure 3. The third step (that is, "check for abnormal conditions") is mainly to check whether there are different models with the same simulated values in the 10 multivariate grey models. If different models have the same simulated values, then using only one of these models can reduce computation (see Section 3.2 for a detailed example).

\section{Numerical Examples}

The Bazimen and Baishuihe landslides in the Three Gorges Reservoir area in China are two examples with significant focus in the study of landslide displacement prediction. Figure 4 shows the geographic location of the Bazimen landslide and the Baishuihe landslide in the Three Gorges Reservoir area. This paper takes these two examples to further illustrate the effectiveness of ICPM.
3.1. Bazimen Landslide. Located on the right bank of Xiangxi River, Xiangxi village, Zigui County, Hubei province, the landslide is $0.8 \mathrm{~km}$ away from the river mouth and $38 \mathrm{~km}$ away from the Three Gorges Dam. The landslide is $350 \mathrm{~m}$ long, 350 500 $\mathrm{m}$ wide, $30 \mathrm{~m}$ in average thickness, and $4 \times 10^{7} \mathrm{~m}^{3}$ in volume. It is an accumulation landslide, and the bank slope is the counter-inclined slope.

The Bazimen landslide was formed in earlier days and belonged to the old landslide. According to the drilling, there are two layers of slip zones in the front, and the upper part is the secondary slip surface. The main slip zone is continuously distributed between the bottom of the slip body and the landslide bed interface, and the inclination of the slip surface is steeper in the middle and rear, about $20^{\circ}$ to $30^{\circ}$. The front part is gently inclined and slightly reversed, and its thickness varies from 0.9 to $3.6 \mathrm{~m}$. The landslide slides along the soil-rock contact surface or the top surface of the flood deposit. The thickness of the slip zone's overall trend is that the front edge and upper part are thin, and the lower part is thick. The slip material is breccia mass, with partial surface being polished and scratched, and the compositions are mainly sandstone and mudstone, filled with silty clay.

The monitoring data of ZG110 and ZG111 monitoring points of the Bazimen landslide from November 2012 to November 2014 were selected (the topographic map of the landslide is shown in Figure 5, and the geological profile is shown in Figure 6). The data unit is on a monthly basis with a total of 25 sets of monitoring data. The first 18 sets of data were used as simulated samples and considered the influence of rainfall and reservoir water level (the grey correlation degree between the landslide displacement data and the 


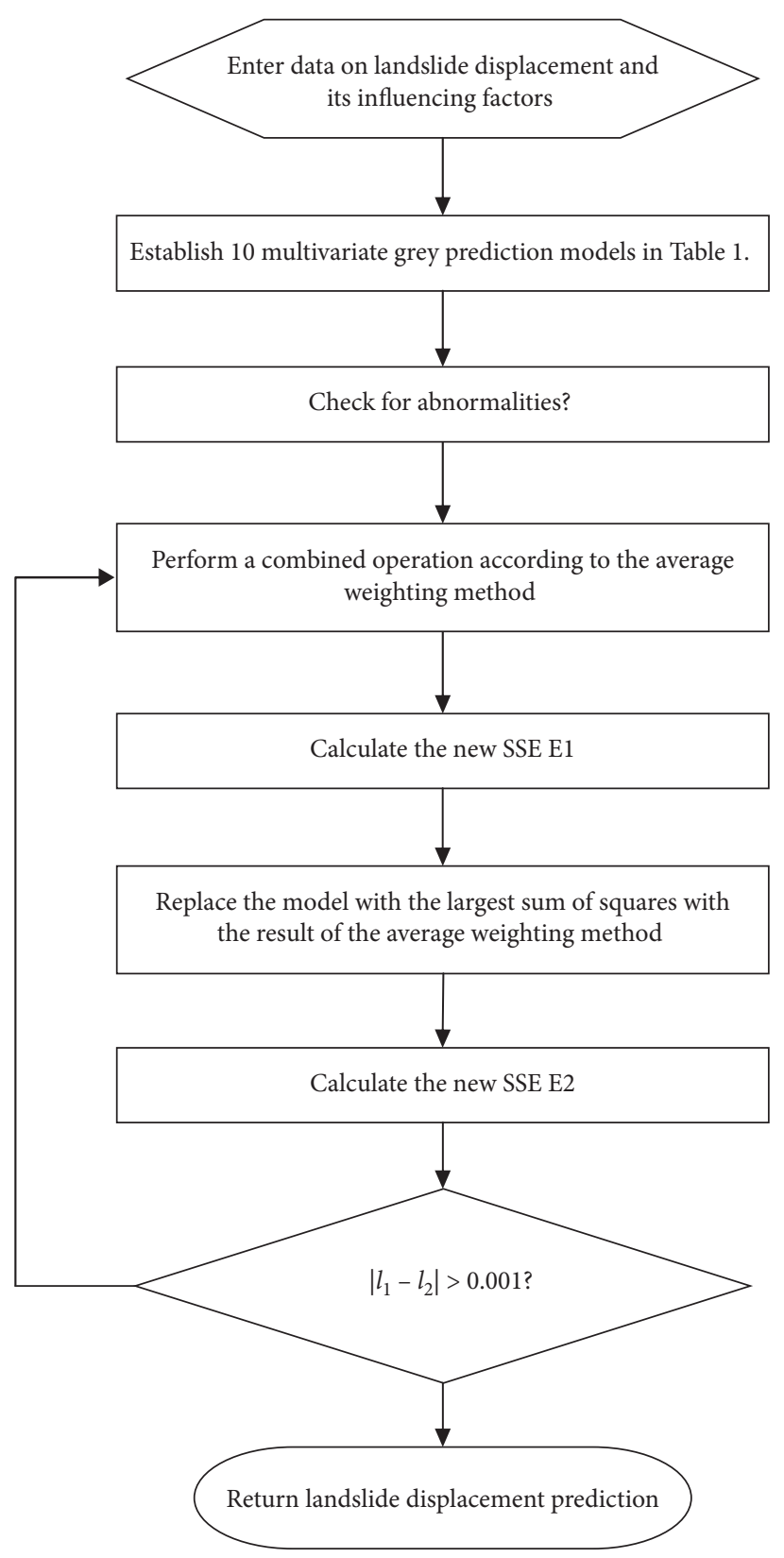

Figure 3: Flow chart of the iteration-based combined prediction method.

rainfall data at ZG111 is 0.60 , and the grey correlation degree between the landslide displacement data and the reservoir water level data is 0.94; the grey correlation degree between the landslide displacement data and the rainfall data at ZG110 is 0.61 , and the grey correlation degree between the landslide displacement data and the reservoir water level data is 0.93 , so the correlation degree calculation results show that it is feasible to use rainfall and reservoir water level as the influencing factors of landslide displacement). The detailed data are shown in Figure 7. It can be seen from Figure 7 that the flood season is concentrated from May to September each year. In July 2014, the rainfall reached the maximum in the two years, and the reservoir water level has a large increase in July and August each year. The annual cumulative displacements measured by GPS monitoring points ZG110 and ZG111 in 2013 were $14.003 \mathrm{~mm}$ and $15.075 \mathrm{~mm}$, respectively, and the annual cumulative displacements measured in 2014 were $11.852 \mathrm{~mm}$ and $14.544 \mathrm{~mm}$, and their average velocity was $1.077 \mathrm{~mm} / \mathrm{month}$ and $1.234 \mathrm{~mm} /$ month, respectively. The cumulative displacement of ZG110 on the frontal part of the landslide grew more quickly than that of ZG111 on the upper part. Moreover, it can be seen from Figure 7 that the cumulative displacement of the monitoring point is affected by the reservoir water level, and there is a sudden increase in the months when the reservoir water level and rainfall change suddenly, with a time interval of $1 \mathrm{a}$.

Figure 8 shows the calculation results of 10 multivariate grey models. It can be seen from the figure that for most prediction models, the prediction results are quite different 


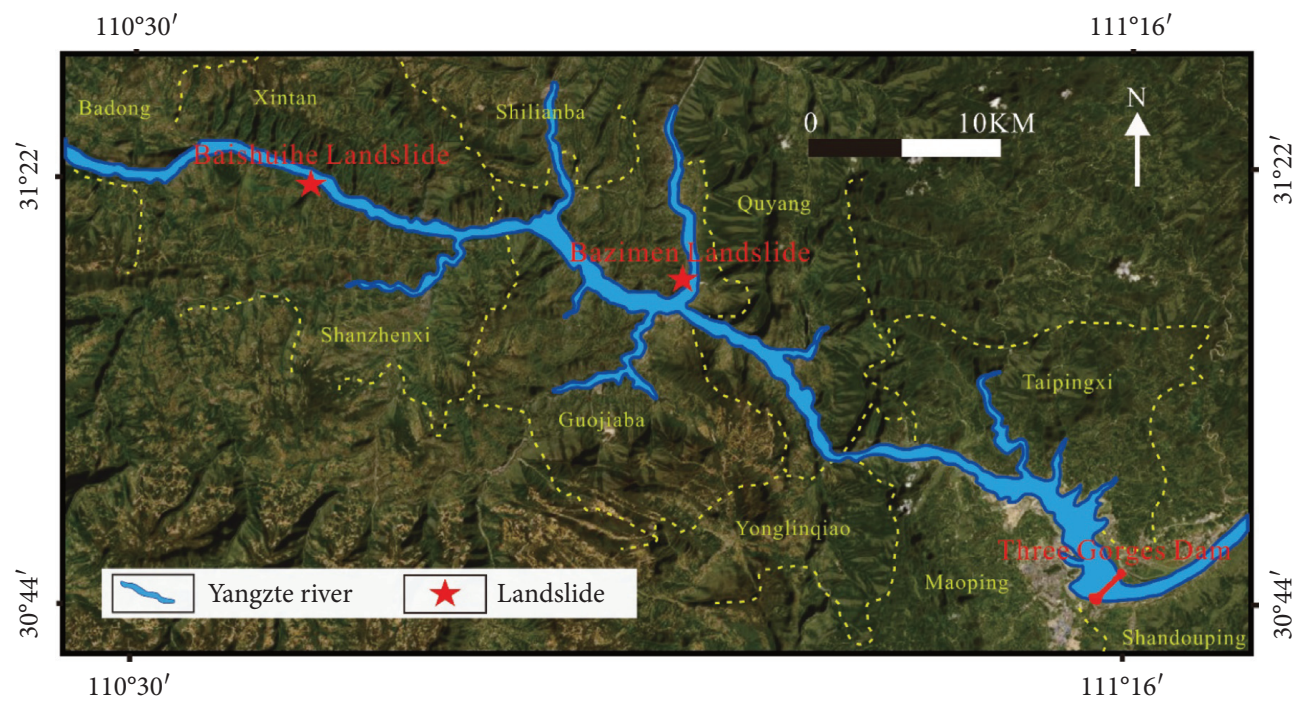

FIgURE 4: Geographic location map of the Bazimen landslide and the Baishuihe landslide.

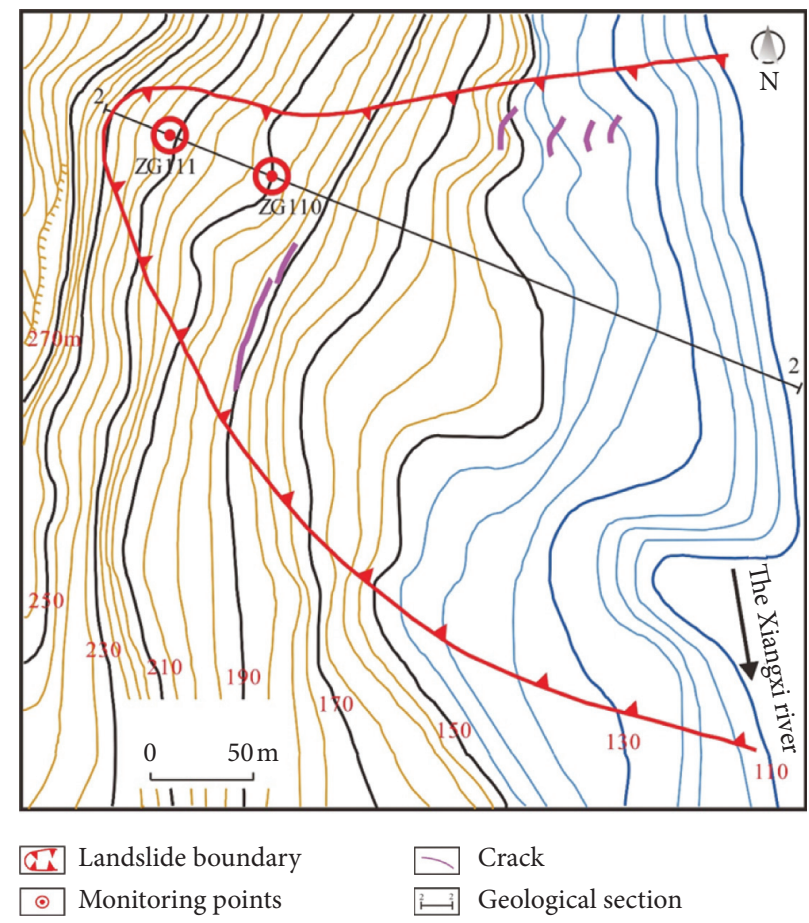

FIgURE 5: Topographic map of the Bazimen landslide.

from the actual values. Among them, the predicted result of FDGM far exceeds the actual value. Only RDGM model's predicted values at the two GPS monitoring points are closer to the actual values. Tables 3 and 4 give the MAPE values of simulated samples and predicted samples of the 10 multivariate grey models, respectively. Tables 5 and 6 give SSE of the 10 multivariate grey models. The FDGM model shows better performance in the Bazimen landslide, while the NGBMC model shows better performance in the Baishuihe landslide.

The calculation results of the 3 combined prediction methods are shown in Figure 9. MAPE and SSE of the 3 combined methods are shown in Tables 7 and 8 according to Figure 8. From the comparison of the simulated samples' results in Tables 3 and 7, it can be seen that the 3 combined models obtain better MAPE than most single models. Only MAPE of FDGM's ZG111 point is 0.488 better than QPCPM. Comparing Tables 4 and 7, MAPE of OWCPM is larger than that of all the single models (the reason for this problem is that the weight calculation is unreasonable, as shown in Figure 10, and the theoretical description is shown in Section 2). QPCPM and ICPM can produce better results than a single model. It can be seen from Table 8 that 2 methods have obtained relatively reliable prediction results. 


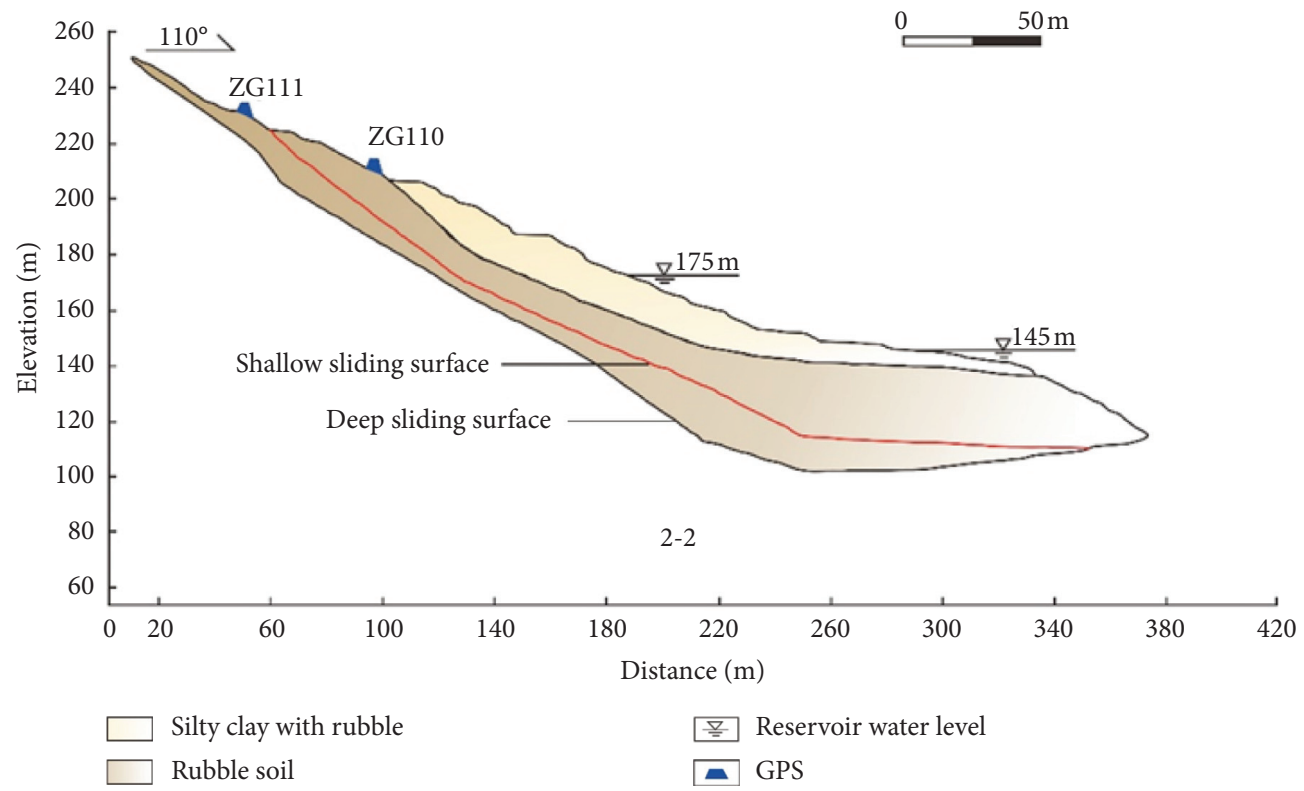

FIgURE 6: Geological section 2-2 of the Bazimen landslide.

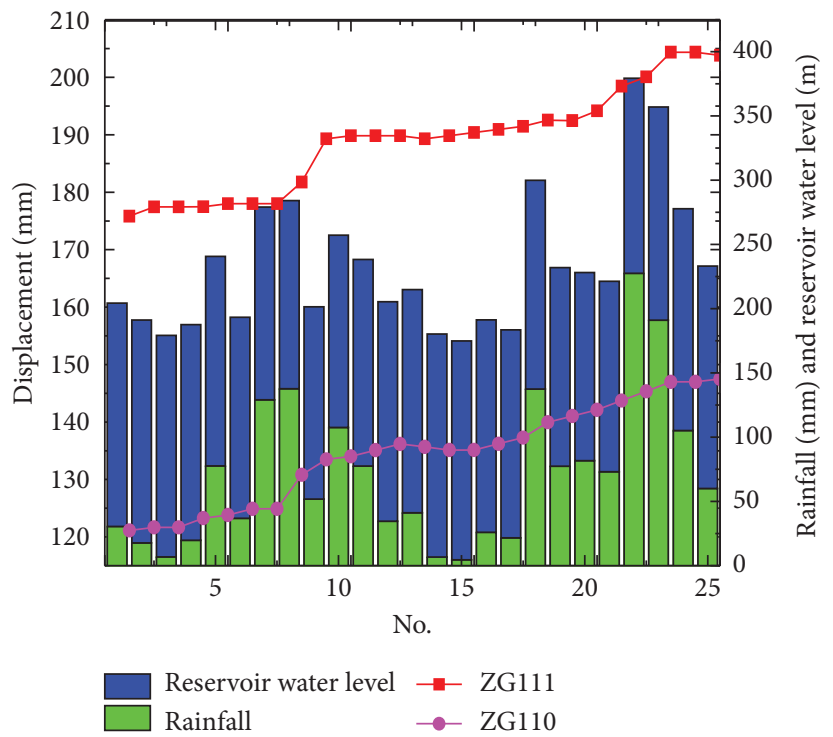

FiguRE 7: Rainfall, reservoir water level, and monitoring point displacement of the Bazimen landslide.

3.2. Baishuihe Landslide. The Baishuihe landslide is located in Zigui County of Three Gorges Reservoir area and on the south bank of the Yangtze River, $56 \mathrm{~km}$ away from the Three Gorges Dam. The landslide's front edge submerges into the Yangtze River, the left and right sides are bounded by the bedrock ridge, and the back edge is bounded by the boundary of the rock and soil. The landslide's main slip direction is about $\mathrm{NE} 20^{\circ}$, with the NS of $600 \mathrm{~m}$ long, the EW of about $700 \mathrm{~m}$ wide, the average thickness of $30 \mathrm{~m}$, and the volume is about $1.26 \times 10^{7} \mathrm{~m}^{3}$. The landslide's front and back edges are relatively steep, and the middle part is relatively gentle. The overall slope is in a "staircase" shape toward the Yangtze River, with an overall slope of $30^{\circ}$.
The Baishuihe landslide is an old landslide and has witnessed many large deformations in history. In June 2003, a lateral crack of more than $300^{\circ} \mathrm{m}$ emerged in the eastern front of landslide. In July 2004, the landslide deformation destroyed 21 houses. From August 2005 to August 2006, sinking and cracking occurred in many places on the landslide surface. On June 30, 2007, a large-scale collapse occurred at the back edge of the early warning zone. In August 2009, the cracks in the western boundary of the landslide spread in a feather-like manner. At present, the landslide presents the characteristics of traction deformation and failure as a whole. The deformation is mainly concentrated in the early warning zone at the front of the 

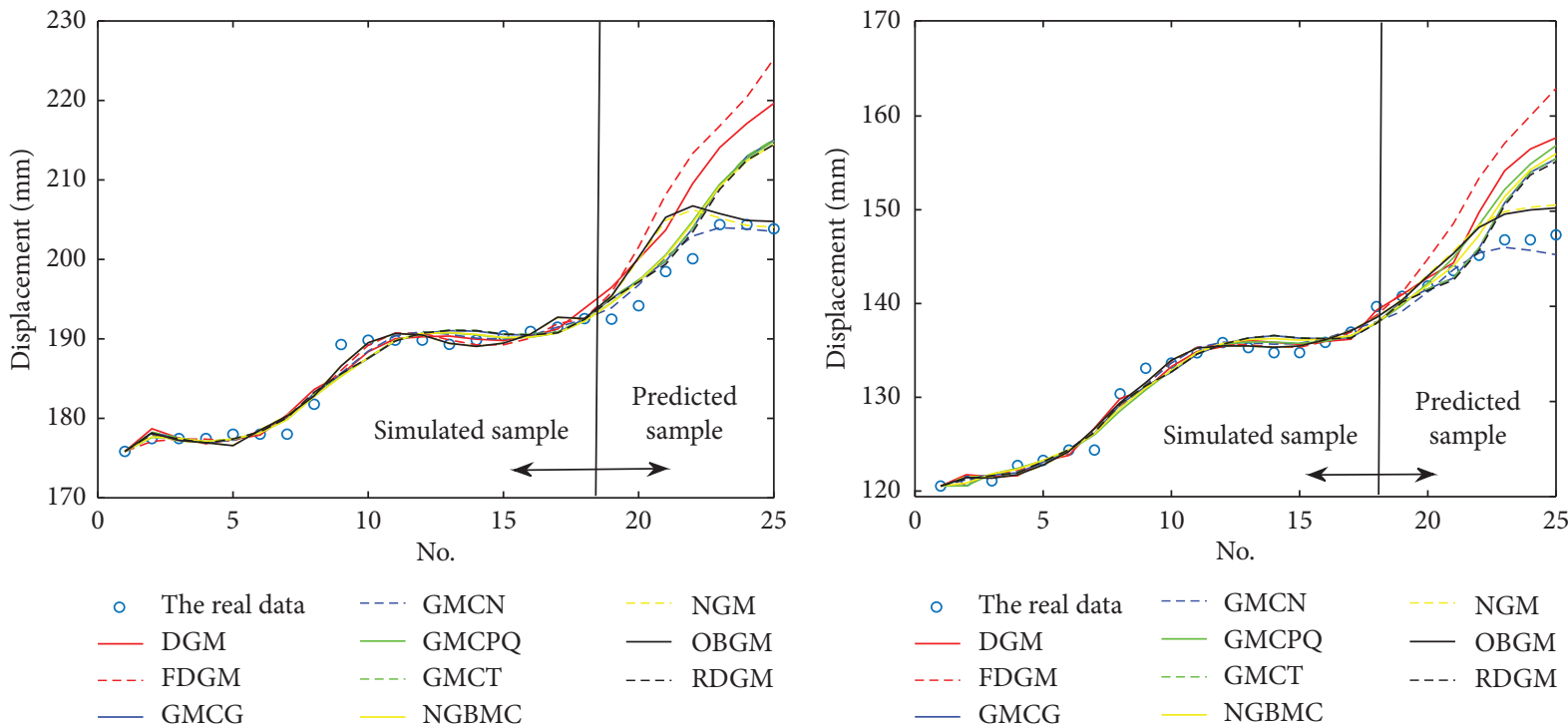

(a)

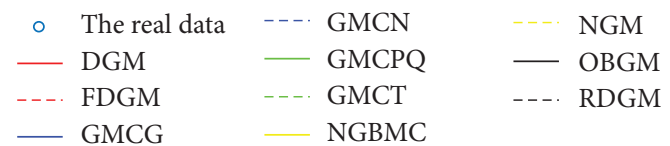

(b)

FIgURE 8: Predicted results of landslide displacement with multivariable grey prediction models.

TABLE 3: MAPE of simulated samples of 10 models (\%).

\begin{tabular}{lcccccccccc}
\hline Monitoring points & DGM & FDGM & GMCG & GMCN & GMCPQ & GMCT & NGBMC & NGM & OBGM & RDGM \\
\hline Bazimen ZG111 & 0.530 & 0.448 & 0.528 & 0.466 & 0.484 & 0.532 & 0.488 & 0.470 & 0.469 & 0.536 \\
Bazimen ZG110 & 0.571 & 0.466 & 0.664 & 0.540 & 0.589 & 0.659 & 0.605 & 0.510 & 0.500 & 0.655 \\
Baishuihe ZG118 & 0.949 & 0.699 & 0.644 & 0.644 & 0.628 & 0.640 & 0.496 & 0.943 & 0.937 & 0.658 \\
Baishuihe XD-01 & 1.188 & 1.003 & 0.917 & 0.917 & 0.904 & 0.872 & 0.843 & 1.204 & 1.201 & 0.928 \\
\hline
\end{tabular}

TABLE 4: MAPE of predicted samples of 10 models (\%).

\begin{tabular}{lcccccccccc}
\hline Monitoring points & DGM & FDGM & GMCG & GMCN & GMCPQ & GMCT & NGBMC & NGM & OBGM & RDGM \\
\hline Bazimen ZG111 & 4.455 & 5.924 & 2.515 & 0.718 & 2.583 & 2.552 & 2.479 & 1.625 & 1.830 & 2.332 \\
Bazimen ZG110 & 3.252 & 5.358 & 2.080 & 0.642 & 2.773 & 2.087 & 2.323 & 1.592 & 1.457 & 2.015 \\
Baishuihe ZG118 & 1.751 & 6.445 & 1.086 & 1.086 & 4.941 & 1.092 & 5.209 & 0.865 & 0.833 & 0.682 \\
Baishuihe XD-01 & 0.750 & 4.975 & 3.998 & 3.998 & 2.849 & 4.184 & 2.641 & 0.482 & 0.504 & 2.749 \\
\hline
\end{tabular}

TABLE 5: SSE of fitting data of 10 models in landslide displacement prediction $\left(/ \mathrm{mm}^{2}\right)$.

\begin{tabular}{lcccccccccc}
\hline Monitoring points & DGM & FDGM & GMCG & GMCN & GMCPQ & GMCT & NGBMC & NGM & OBGM & RDGM \\
\hline Bazimen ZG111 & 1.876 & 1.300 & 1.888 & 1.529 & 1.778 & 1.891 & 1.794 & 1.243 & 1.246 & 1.895 \\
Bazimen ZG110 & 0.940 & 0.682 & 1.170 & 0.906 & 1.075 & 1.165 & 1.091 & 0.721 & 0.723 & 1.172 \\
Baishuihe ZG118 & 447.886 & 459.246 & & 226.613 & 320.647 & 225.020 & 157.201 & 444.255 & 452.005 & 229.084 \\
Baishuihe XD-01 & 1446.069 & 1253.000 & & 827.297 & 965.870 & 817.770 & 819.942 & 1419.108 & 1421.556 & 841.205 \\
\hline
\end{tabular}

TABLE 6: SSE of prediction data of 10 models in landslide displacement prediction $\left(/ \mathrm{mm}^{2}\right)$.

\begin{tabular}{lcccccccccc}
\hline Monitoring points & DGM & FDGM & GMCG & GMCN & GMCPQ & GMCT & NGBMC & NGM & OBGM & RDGM \\
\hline Bazimen ZG111 & 96.084 & 171.999 & 36.374 & 2.954 & 36.807 & 37.164 & 34.033 & 17.542 & 19.942 & 32.115 \\
Bazimen ZG110 & 38.530 & 86.882 & 18.699 & 1.297 & 27.485 & 18.866 & 21.851 & 6.590 & 5.479 & 17.209 \\
Baishuihe ZG118 & 1548.047 & 20822.051 & & 732.390 & 12418.621 & 741.033 & 13358.088 & 483.450 & 406.279 & 475.609 \\
Baishuihe XD-01 & 540.880 & 21915.754 & & 17381.511 & 8042.872 & 18766.060 & 5952.347 & 221.817 & 303.639 & 7932.103 \\
\hline
\end{tabular}




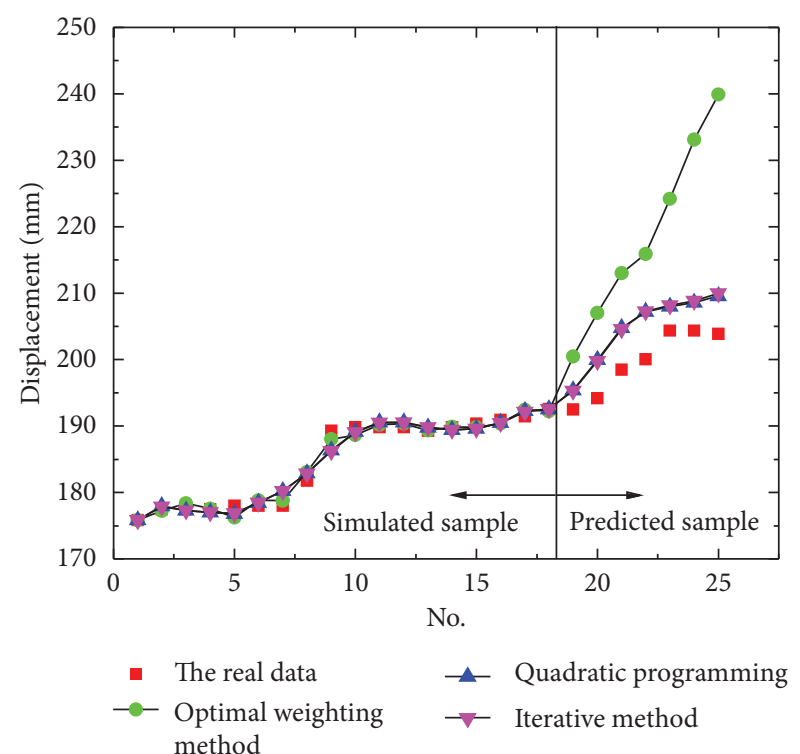

(a)

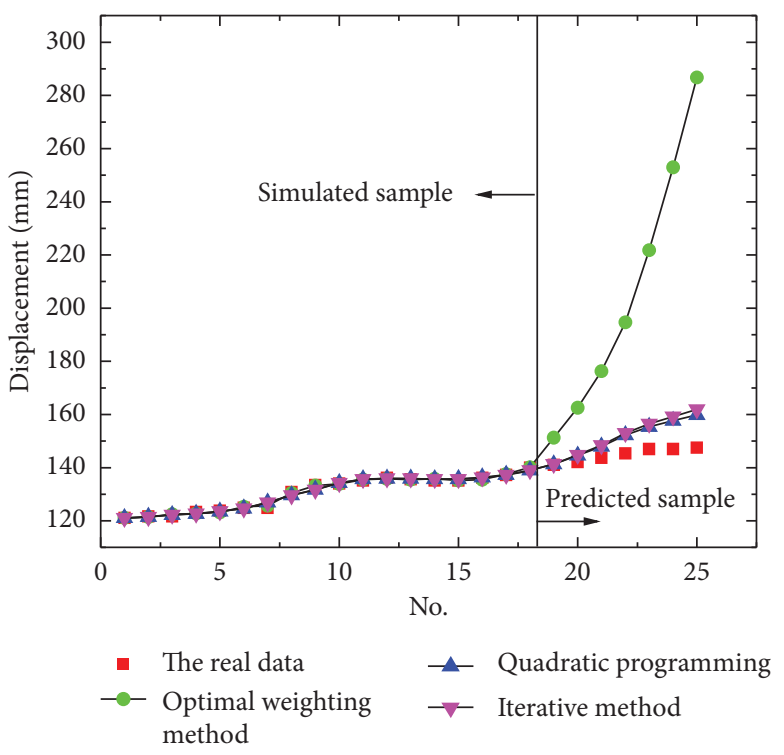

(b)

FIgure 9: Prediction of the displacement of the Bazimen landslide by 3 combined methods: (a) ZG111; (b) ZG110.

TABLE 7: MAPE of 3 combined prediction methods (/\%).

\begin{tabular}{llccrr}
\hline \multirow{2}{*}{ Method } & & Bazimen & & Baishuihe \\
& & ZG111 & ZG110 & ZG118 & 0.353 \\
OWCPM & Simulation & 0.372 & 0.314 & 1.460 \\
& Prediction & 9.636 & 42.205 & 0.468 \\
QPCPM & Simulation & 0.450 & 0.466 & 3.617 & 0.7225 \\
& Prediction & 2.555 & 4.412 & 0.526 \\
ICPM & Simulation & 0.448 & 0.466 & 2.952 & 0.732 \\
& Prediction & 2.580 & 5.028 & & 1.2657 \\
\hline
\end{tabular}

TABLE 8: SSE of 3 combined prediction methods $\left(/ \mathrm{mm}^{2}\right)$.

\begin{tabular}{|c|c|c|c|c|c|}
\hline \multirow{2}{*}{ Method } & & \multicolumn{2}{|c|}{ Bazimen } & \multicolumn{2}{|c|}{ Baishuihe } \\
\hline & & ZG111 & ZG110 & ZG118 & XD-01 \\
\hline \multirow{2}{*}{ OWCPM } & Simulation & 0.707 & 0.221 & 66.204 & 345.730 \\
\hline & Prediction & 458.470 & 5743.774 & 1687.825 & 64156.852 \\
\hline \multirow{2}{*}{ QPCPM } & Simulation & 1.198 & 0.677 & 130.614 & 679.368 \\
\hline & Prediction & 28.051 & 58.271 & 6431.539 & 685.800 \\
\hline \multirow{2}{*}{ ICPM } & Simulation & 1.221 & 0.682 & 145.639 & 757.375 \\
\hline & Prediction & 28.572 & 76.464 & 4307.895 & 1499.711 \\
\hline
\end{tabular}

landslide, and the displacement of the monitoring point at the rear is relatively stable.

The monitoring data of the Baishuihe landslide from January 2010 to December 2011 are selected (the landslide topographic map is shown in Figure 11, the geological profile is shown in Figure 12, and the monitoring data are shown in Figure 13). The monitoring point's cumulative displacement continues to increase, and the maximum displacement increase rate occurs during the reservoir water level's falling to the bottom level. The annual increase value of cumulative displacement of ZG118 is $156.1 \mathrm{~mm}$ and $146.34 \mathrm{~mm}$, respectively, and the annual increase value of cumulative displacement of XD01 is $263.42 \mathrm{~mm}$ and $185.37 \mathrm{~mm}$, respectively. It can be seen that the cumulative displacement of XD01 increases faster than that of ZG118. With the longterm adjustment of the reservoir water level, the landslide has undergone long-term stress adjustment. The landslide gradually adapts to the new reservoir scheduling mode, and its displacement growth tends to be stable.

The former 18 sets of data are still used to establish the model (the grey correlation degree between the landslide displacement data at ZG118 and the rainfall data is 0.71 , and 


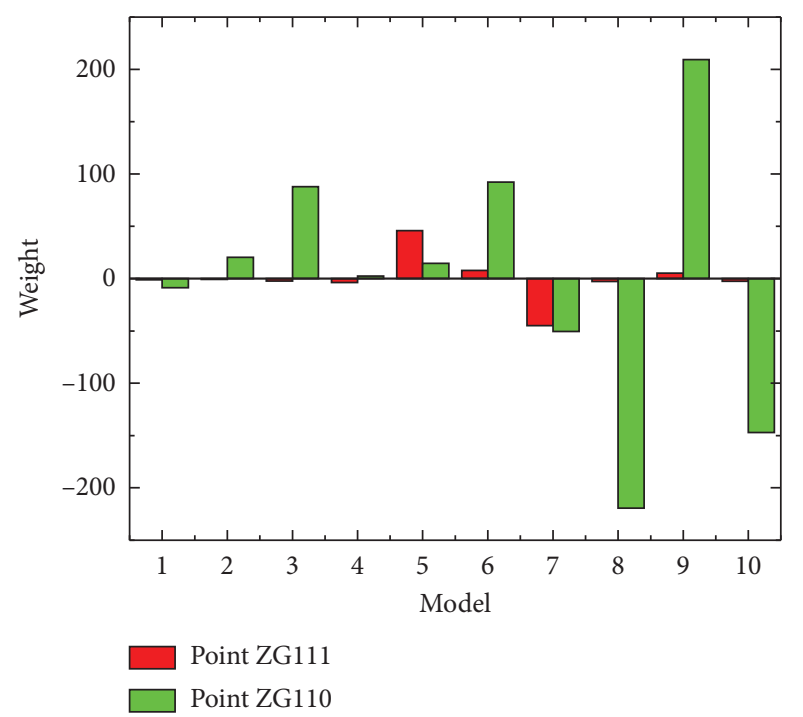

(a)

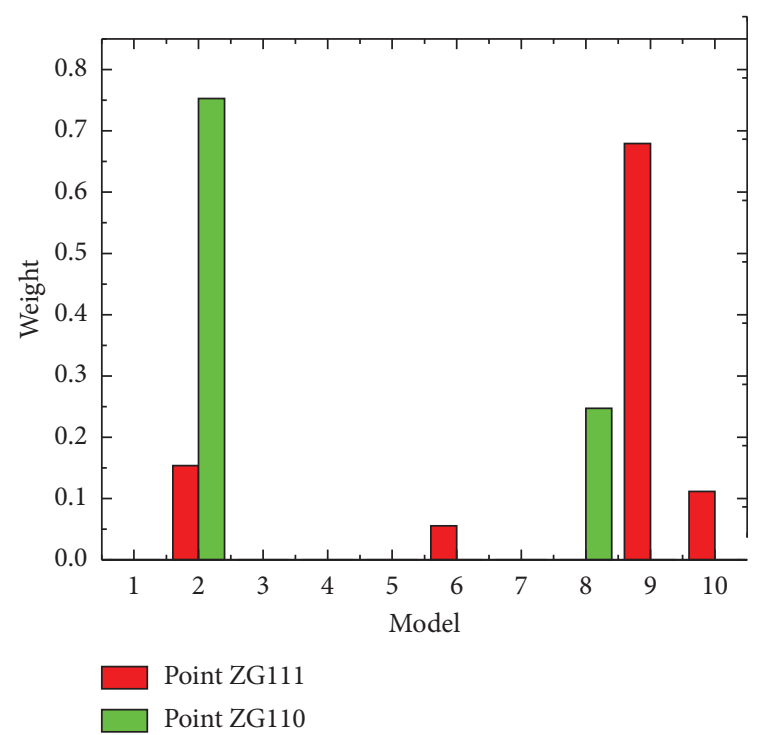

(b)

FIGURE 10: Weights of different combined methods (the Bazimen landslide): (a) OWCPM; (b) QPCPM.

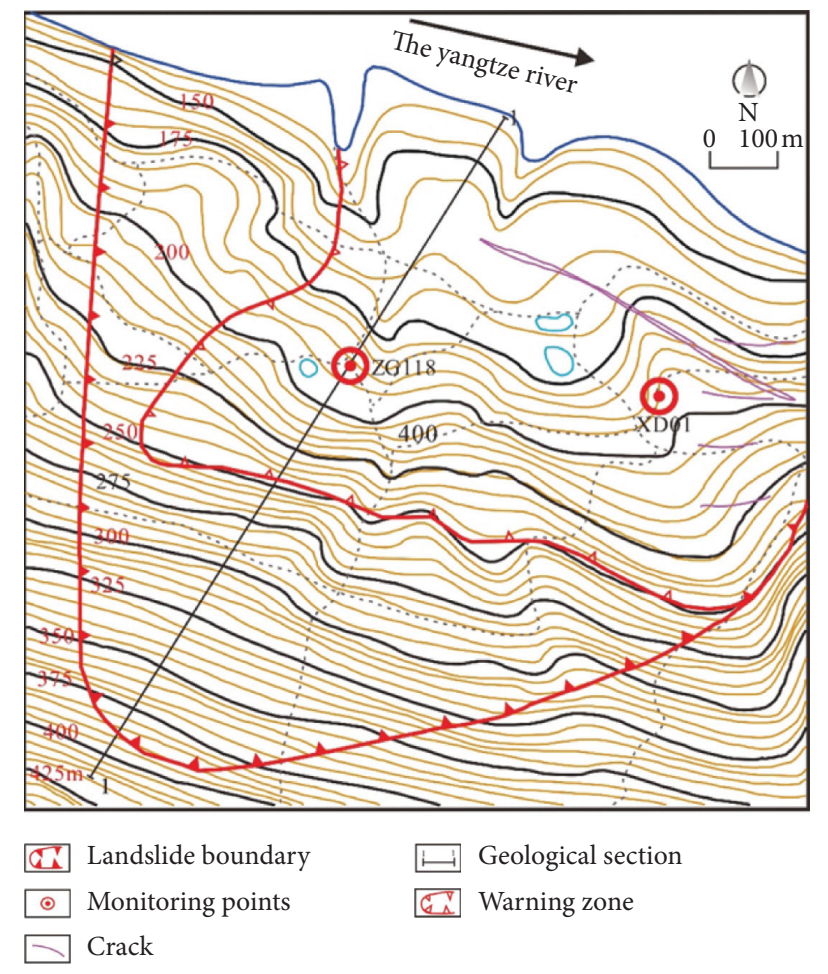

Figure 11: Geographic location map of the Baishuihe landslide.

the grey correlation degree between ZG118 and the reservoir water level data is 0.96; the grey correlation degree between the landslide displacement data and the rainfall data at ZG110 is 0.70 , and the grey correlation degree between ZG110 and the reservoir water level data is 0.96 . The correlation degree calculation indicates that it is feasible to use rainfall and reservoir water levels as factors influencing landslide displacement). Figure 14 provides the results of 10 multivariate grey prediction models. Figure 15 provides the prediction results of 3 combined methods. The simulated and predicted samples' MAPE and SSE in Tables 3-6 can be calculated from Figure 14. MAPE and SSE of the three methods derived from Figure 15 are shown in Tables 7 and 8, respectively. It is worth noting that the 10 multivariate grey prediction models obtained very different results at 2 GPS monitoring points. In the prediction results of ZG118, the FDGM model showed promising results, and the NGM model showed good performance in the prediction results of 


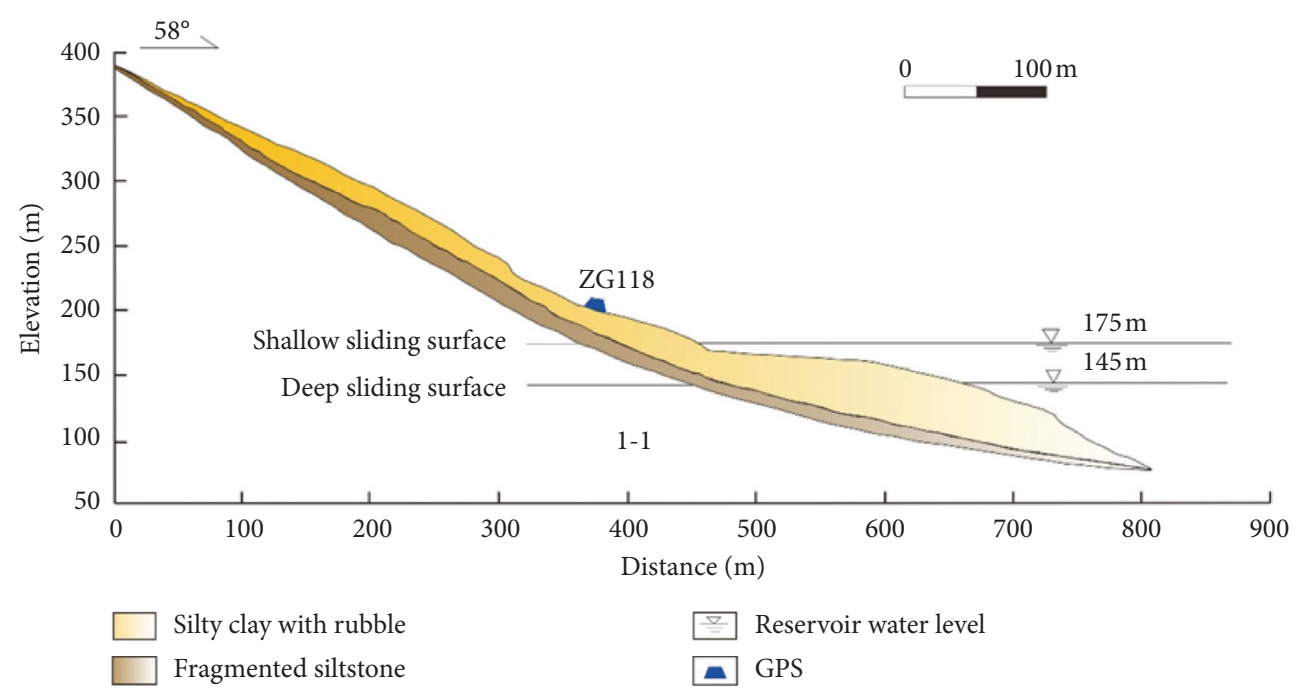

Figure 12: Geological section 1-1 of the Baishuihe landslide.

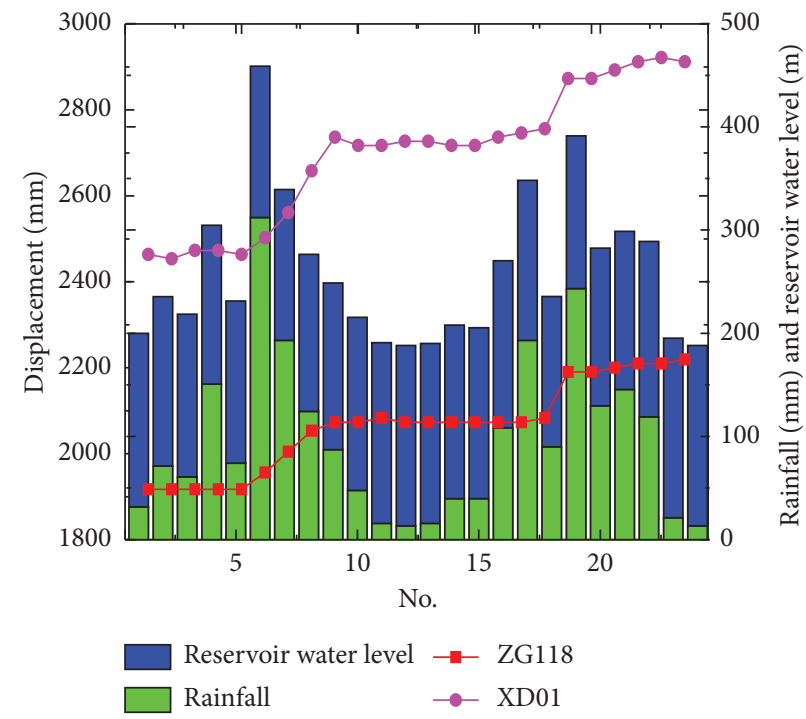

FIGURE 13: Rainfall, reservoir water level, and monitoring point displacement of the Baishuihe landslide.

XD01. However, the overall effect of using a single method is not satisfactory. It can be seen from Table 7 that MAPE value of OWCPM is the smallest at ZG118, and the minimum MAPE at XD01 is QPCPM. The difference is also confirmed in Figure 15.

Based on the above two examples, it can be seen that it is beset with difficulties to only rely on a single model to predict landslide displacement. For example, in the Bazimen landslide, FDGM achieves the best performance on the simulated samples. According to the general standard, the prediction results of FDGM are considered reliable. Unfortunately, the calculation of prediction samples shows that the prediction performance of FDGM is not good. OWCPM is not recommended in practice because of its theoretical flaws. In terms of calculation results, although QPCPM is better than ICPM, the relative level of the prediction performance of the two methods is at random. In the Bazimen landslide simulation samples, the two combined methods' MAPE and SSE are very close. However, MAPE of QPCPM is slightly lower than that of ICPM in prediction samples (MAPE of QPCPM is $2.555 \%$ and $4.412 \%$; MAPE of ICPM is $2.580 \%$ and $5.028 \%$; SSE of QPCPM is $28.051 \mathrm{~mm}^{2}$ and $58.271 \mathrm{~mm}^{2}$; and SSE of ICPM is $28.272 \mathrm{~mm}^{2}$ and $76.464 \mathrm{~mm}^{2}$ ). In the Baishuihe landslide, the prediction samples based on QPCPM have a lower MAPE in ZG118 than ICPM, while the prediction samples' results at XD01 are the opposite. Therefore, the iteration-based combined prediction method is still recommended in terms of computational complexity.

\section{Discussion}

Prediction of landslide displacement plays an essential role in reducing landslide disaster damage. A large number of 


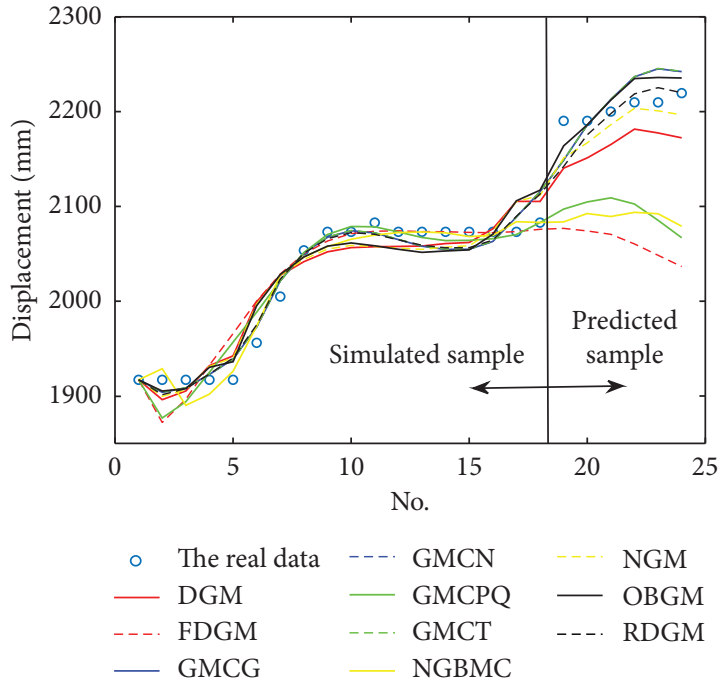

(a)

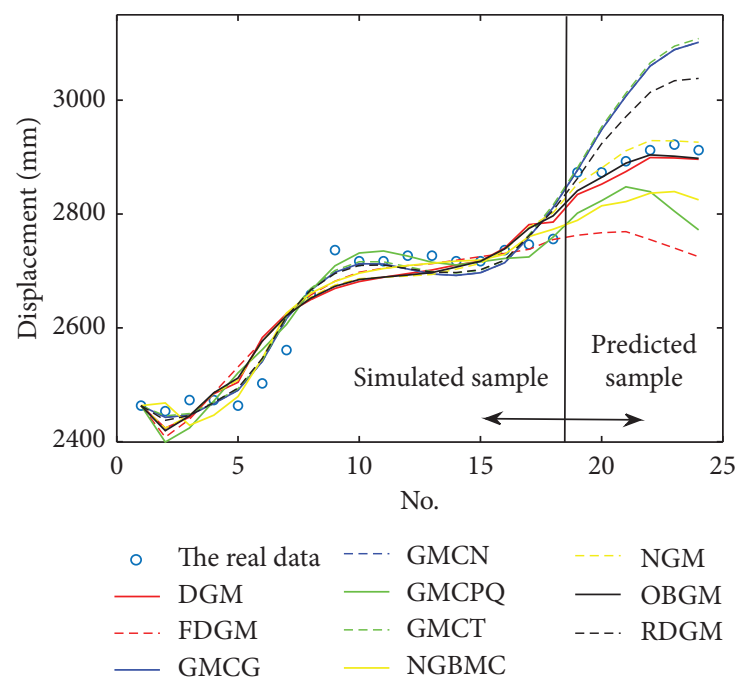

(b)

FIGURE 14: Prediction of displacement of the Baishuihe landslide by 10 multivariate grey prediction models: (a) ZG118; (b) XD-01.

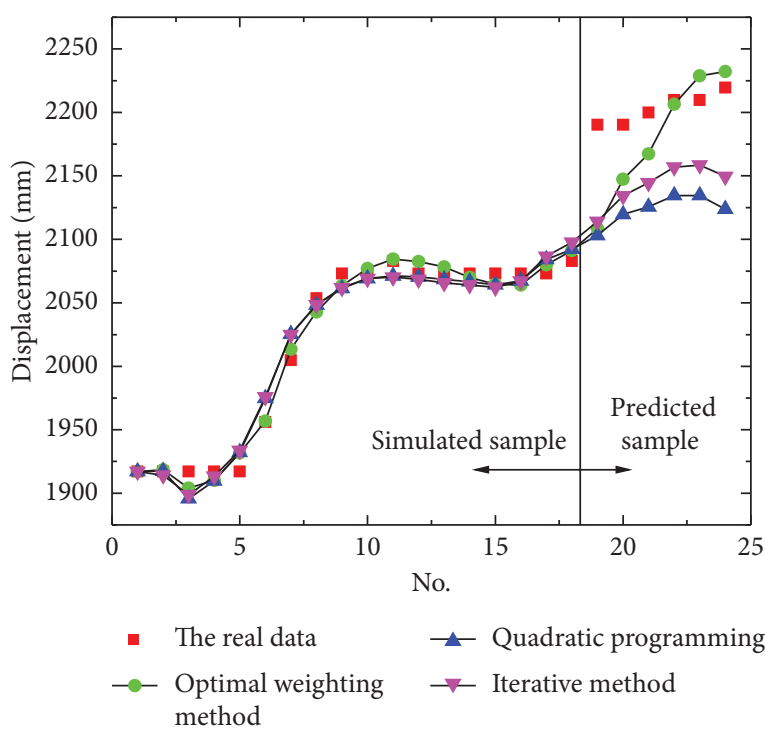

(a)

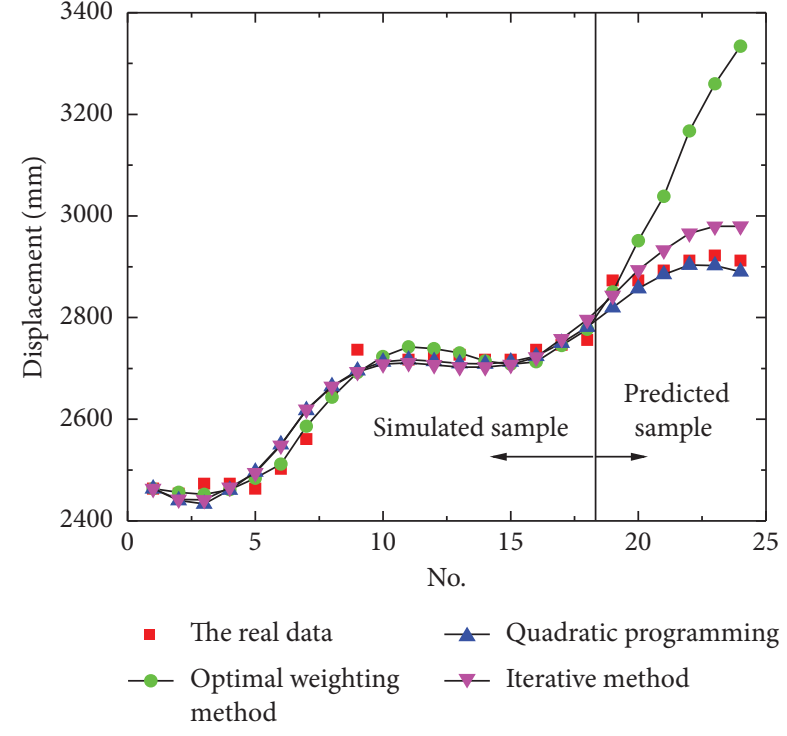

(b)

FIGURE 15: Prediction of displacement of the Baishuihe landslide by 3 combined methods: (a) ZG118; (b) XD-01.

landslide displacement prediction models have been proposed. However, as Intrieri et al. [29] pointed out: "Nonetheless, this field has experienced a great pulse of research development in the very recent past, even to the point that the literature seems to be quite redundant and not conclusive." Many papers have proposed the prediction methods of landslide displacement prediction, but their effectiveness is obtained only by one example and lacks explicit elaboration for the method's mathematical properties. The combined strategies are elaborated in this paper. Since the optimal weight strategy does not restrict the weights' positive and negative properties, this paper adds the restriction conditions in equation (14) to the optimal weight strategy to obtain the quadratic programming problem. Simultaneously, to avoid a complicated solution process, the value of the prediction model corresponding to $J_{\max }$ is replaced with the predicted value corresponding to $J_{a}$, and ICPM can be obtained.

Artificial neural networks are often used for landslide displacement prediction. A landslide displacement prediction method based on the ANNs-switched method was proposed by Lian et al. [30]. This method considers rainfall and reservoir level elevation as parameters as in this paper. MAPE of predicted samples of the ANNs-switched 
prediction method in the Bazimen landslide is $1.8940 \%$. Its predicted performance is higher than 7 of the 10 latest grey multivariate prediction models. Only the performance of GMCN, NGM, and OBGM is slightly better than the ANNsswitched prediction method.

It can be concluded from Tables 7 and 8 that regardless of whether MAPE or SSE is considered, the performance of the prediction method using the combined strategy is better than that of the ANNs-switched prediction method. However, due to OWCPM's theoretical flaws, the results in the predicted samples of the Bazimen landslide are not satisfactory. At the same time, it was also found that the MAPE and SSE of QPCPM and ICPM are also very close. Therefore, in the actual use of these two prediction methods, very similar results can be obtained. Nevertheless, QPCPM has too much calculation and is not a convenient method. As a simplified QPCPM, ICPM greatly simplifies the calculation and reduces the complexity. Its mathematical reliability is proven in Section 2.3.

A suitable landslide displacement prediction method must have a relatively minor simulated error and predicted error. However, the prediction method applicable to all landslides does not exist. The same prediction method has different performances on different landslide samples. To be precise, ICPM cannot be regarded as an accurate method but a method with high reliability. It is worth noting that the proposed method cannot be applied for regions where soils may exhibit considerable strain softening, which may trigger sudden rapid dynamic landslide movement such as that occurred during the Vaiont landslide [31-33].

\section{Conclusions}

In this paper, an iteration-based combined strategy for landslide displacement is proposed. The conclusions are as follows:

(1) ICPM is based on the 10 latest multivariate grey prediction models' calculation. The proposed method obtains the predicted value of landslide displacement by simple iterative calculation, which has the advantages of simplicity and high reliability.

(2) It proved that OWCPM is challenged to guarantee the prediction performance, and it is not recommended to use it in practice. Compared with QPCPM, ICPM has low complexity and is convenient for engineers to adopt.

(3) The landslide displacement prediction cases indicate that ICPM is useful, and the method is expected to be applied in engineering.

\section{Data Availability}

The data used to support the findings of this study are included within the article.

\section{Conflicts of Interest}

The authors declare that they have no conflicts of interest.

\section{Acknowledgments}

The authors thank the Scientific and Technological Research Program of Chongqing Municipal Education Commission (grant nos. KJQN201901221, KJQN201901239, KJQN201901241, KJQN202001218, and KJQN202001219) and General Program of Chongqing Natural Science Foundation (grant no. cstc2019jcyj-mscm1865).

\section{References}

[1] A. Segalini, A. Valletta, and A. Carri, "Landslide time-of-failure forecast and alert threshold assessment: a generalized criterion," Engineering Geology, vol. 245, pp. 72-80, 2018.

[2] T. Fukuzono, "A new method for predicting the failure time of a slope failure," in Proceedings of the 4th International Conference and Field Workshop on Landslides, pp. 145-150, Tokyo, Japan, August 1985.

[3] E. Lacasse, "Twenty-ninth Canadian Geotechnical Colloquium: the role of advanced numerical methods and geotechnical field measurements in understanding complex deep-seated rock slope failure mechanisms," Canadian Geotechnical Journal, vol. 45, no. 4, pp. 484-510, 2008.

[4] F. Huang, J. Huang, S. Jiang, and C. Zhou, "Landslide displacement prediction based on multivariate chaotic model and extreme learning machine," Engineering Geology, vol. 218, pp. 173-186, 2017.

[5] F. M. Huang, K. L. Yin, G. R. Zhang, L. Gui, B. B. Yang, and L. Liu, "Landslide displacement prediction using discrete wavelet transform and extreme learning machine based on chaos theory," Environmental Earth Sciences, vol. 75, p. 1376, 2016.

[6] Y. Liu, D. Liu, Z. Qin, F. Liu, and L. Liu, "Rainfall data feature extraction and its verification in displacement prediction of Baishuihe landslide in China," Bulletin of Engineering Geology and the Environment, vol. 75, no. 3, pp. 897-907, 2016.

[7] X.-T. Feng, H. Zhao, and S. Li, "Modeling non-linear displacement time series of geo-materials using evolutionary support vector machines," International Journal of Rock Mechanics and Mining Sciences, vol. 41, no. 7, pp. 1087-1107, 2004.

[8] C. Lian, Z. Zeng, W. Yao, and H. Tang, "Displacement prediction model of landslide based on a modified ensemble empirical mode decomposition and extreme learning machine," Natural Hazards, vol. 66, no. 2, pp. 759-771, 2013.

[9] F. Huang, J. Huang, S.-H. Jiang, and C. Zhou, "Prediction of groundwater levels using evidence of chaos and support vector machine," Journal of Hydroinformatics, vol. 19, no. 4, pp. 586-606, 2017.

[10] V. Du and K. Yin, "Displacement prediction in colluvial landslides, three Gorges reservoir, China," Landslides, vol. 10, no. 2, pp. 203-218, 2013.

[11] K. V. Shihabudheen, G. N. Pillai, and B. Peethambaran, "Prediction of landslide displacement with controlling factors using extreme learning adaptive neuro-fuzzy inference system (ELANFIS)," Applied Soft Computing, vol. 61, pp. 892-904, 2017.

[12] C. Zhou, K. Yin, Y. Cao, E. Intrieri, B. Ahmed, and F. Catani, "Displacement prediction of step-like landslide by applying a novel kernel extreme learning machine method," Landslides, vol. 15, no. 11, pp. 2211-2225, 2018.

[13] Z. Cai, W. Xu, Y. Meng, C. Shi, and R. Wang, "Prediction of landslide displacement based on GA-LSSVM with multiple 
factors," Bulletin of Engineering Geology and the Environment, vol. 75, no. 2, pp. 637-646, 2016.

[14] K. Liao, Y. Wu, F. Miao, L. Li, and Y. Xue, "Using a kernel extreme learning machine with grey wolf optimization to predict the displacement of step-like landslide," Bulletin of Engineering Geology and the Environment, vol. 79, no. 2, pp. 673-685, 2019.

[15] J. M. Bates and C. W. J. Granger, "The combination of forecasts," Operational Research Quarterly, vol. 20, no. 4, pp. 150-157, 1969.

[16] D. Bunn, "Forecasting with more than one model," Journal of Forecasting, vol. 8, no. 3, pp. 161-166, 1989.

[17] X. Li, J. Kong, and Z. Wang, "Landslide displacement prediction based on combining method with optimal weight," Natural Hazards, vol. 61, no. 2, pp. 635-646, 2012.

[18] T. Tzu-Li, "A research on the grey prediction model GM(1,N)," Applied Mathematics and Computation, vol. 218, no. 9, pp. 4903-4916, 2012.

[19] X. Ma and Z.-B. Liu, "Research on the novel recursive discrete multivariate grey prediction model and its applications," Applied Mathematical Modelling, vol. 40, no. 7-8, pp. 48764890, 2016.

[20] S. Ding, "A novel discrete grey multivariable model and its application in forecasting the output value of China's hightech industries," Computers \& Industrial Engineering, vol. 127, pp. 749-760, 2019.

[21] X. Ma, Z. Liu, and Y. Wang, "Application of a novel nonlinear multivariate grey Bernoulli model to predict the tourist income of China," Journal of Computational and Applied Mathematics, vol. 347, pp. 84-94, 2019.

[22] L. Wu and Z. Zhang, "Grey multivariable convolution model with new information priority accumulation," Applied Mathematical Modelling, vol. 62, pp. 595-604, 2018.

[23] L. Wu, X. Gao, Y. Xiao, Y. Yang, and X. Chen, "Using a novel multi-variable grey model to forecast the electricity consumption of Shandong Province in China," Energy, vol. 157, no. 15 , pp. $327-335,2018$.

[24] X. Ma, M. Xie, W. Wu, B. Zeng, Y. Wang, and X. Wu, “The novel fractional discrete multivariate grey system model and its applications," Applied Mathematical Modelling, vol. 70, pp. 402-424, 2019.

[25] B. Zeng, C. Luo, S. Liu, and C. Li, "A novel multi-variable grey forecasting model and its application in forecasting the amount of motor vehicles in Beijing," Computers \& Industrial Engineering, vol. 101, pp. 479-489, 2016.

[26] B. Zeng and C. Li, "Improved multi-variable grey forecasting model with a dynamic background-value coefficient and its application," Computers \& Industrial Engineering, vol. 118, pp. 278-290, 2018.

[27] X. Ma and Z.-B. Liu, "The kernel-based nonlinear multivariate grey model," Applied Mathematical Modelling, vol. 56, pp. 217-238, 2018.

[28] Math Manual Writing Group, Mathematics Handbook, Higher Education Press, Beijing, China, 2008, in Chinese.

[29] E. Intrieri, T. Carlà, and G. Gigli, "Forecasting the time of failure of landslides at slope-scale: a literature review," EarthScience Reviews, vol. 193, pp. 333-349, 2019.

[30] C. Lian, Z. Zeng, W. Yao, and H. Tang, "Multiple neural networks switched prediction for landslide displacement," Engineering Geology, vol. 186, pp. 91-99, 2015.

[31] M. Ciabati, "La dinamica della frana del Vaiont," Geology, vol. 32, pp. 139-154, 1964.

[32] C. A. Stamatopoulos and B. Di, "Analytical and approximate expressions predicting post-failure landslide displacement using the multi-block model and energy methods," Landslides, vol. 12, no. 6, pp. 1207-1213, 2015.

[33] T. E. Tika and J. N. Hutchinson, "Ring shear tests on soil from the Vaiont landslide slip surface," Géotechnique, vol. 49, no. 1, pp. 59-74, 1999. 